\title{
MEASURING THE EFFECT OF ENVIRONMENTAL STRESS ON CELL SURVIVAL DURING REPLICATION STRESS
}

\author{
by \\ Poojaben Patel \\ Master of Science, Saurashtra University, India, 2009 \\ Bachelor of Science, Saurashtra University, India, 2007 \\ A thesis presented to Ryerson University \\ in partial fulfillment of the requirements for the degree of \\ Master of Science \\ in the program of Molecular Science
}

Toronto, Ontario, Canada, 2017

(C) Poojaben Patel, 2017 


\section{Declaration}

I hereby declare that I am the sole author of this thesis. This is a true copy of the thesis, including any required final revisions, as accepted by my examiners.

I authorize Ryerson University to lend this thesis to other institutions or individuals for the purpose of scholarly research.

I further authorize Ryerson University to reproduce this thesis by photocopying or by other means, in total or in part, at the request of other institutions or individuals for the purpose of scholarly research.

I understand that my thesis may be made electronically available to the public. 


\section{Abstract}

\section{Measuring the Effect of Environmental Stress on Cell Survival during Replication Stress}

Poojaben Patel, Master of Science in Molecular Science, Ryerson University, 2017

DNA replication checkpoint ensures cell fitness under replication stress by restraining fork progression and arresting cell cycle. Without checkpoint proteins, cells die in a replication inhibitor hydroxyurea (HU). However, cellular environment may affect their survival in HU. Therefore, the main goal of this study was to examine the effect of environmental stress and to study how it promotes survival in replication checkpoint mutants of fission yeast $(\operatorname{rad} 3 \Delta, \operatorname{mrc1} \Delta, c d s 1 \Delta)$. Our viability assays showed a significant increase in these mutants survival in heat-shock + HU compared to HU alone. Cell-cycle staging suggests that cells are altered after heat shock, affecting their response to HU. We measured the consequences to this enhanced survival and found that surviving population exhibits altered DNA mis-segregation and mutation rate. Collectively, our work points to a general cellular response to various environmental stressors that affects survival under replication stress, and may be applicable to human disease. 


\section{Acknowledgements}

Achievement of a goal is not one person's job. It is obtained by guidance and cooperation of others. Foremost, I would like to express my heartfelt gratitude to my adviser, Dr. Sarah Sabatinos for her patience, motivation, enthusiasm, and profound knowledge. Her continuous guidance and feedback helped me to not only improve the quality of my research but also my writing and presentation skills.

I would like to express my sincere appreciation to my committee members, Dr. Jeffrey Fillingham and Dr. Costin Antonescu for their valuable suggestions on my research work. I specially thank to Kyle Cheung for his invaluable assistance with experiments. Many thanks to the entire Sabatinos team and Nora Dannah who helped me one way or another throughout the journey. Without them, it would have not been possible to take pleasure in so many lighter moments happening throughout the day.

I am deeply thankful to the Fillingham Lab for all the facilities and resources that they provided to make my work effective. I would also like to thank Sarah Kovacs and Stephanie Grouios for providing information whenever I needed. Many thanks to Ryerson university, NSERC Discovery Grant program, and a Ryerson Faculty of Science Dean's Research Fund Award for funding my work. 
I spent so much time discussing my thesis problems and work stress with the most encouraging person, my husband, Raj, who supported me the most to achieve my goal, and I can not find the word to express my appreciation to him. My thesis work was unthinkable without another wonderful person in my life, my brother, Sujay, who not only solved the technical issues anytime I had created one but also proof read my writing throughout my studies.

Finally, I would like to write in only one sentence that my thesis is not complete without all these "personalities". I wish my association with all these persons would continue in science. 


\section{Dedication}

Dedicated to my kindhearted parents and supportive mother-in-law, for their unconditional and unceasing love, belief and support. Also, to the entire research community, who with their hard work, make this world a better place! 


\section{Contents}

$\begin{array}{lll}\text { Abstract } & \text { iii }\end{array}$

Acknowledgement $\quad$ iv

List of Tables $\quad$ x

List of Figures $\quad$ xii

List of Abbreviations $\quad$ Xv

$\begin{array}{ll}\text { Chapter 1: Introduction } & 1\end{array}$

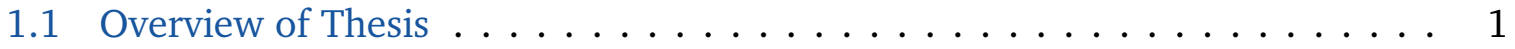

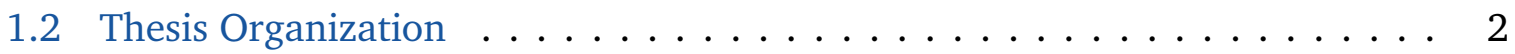

Chapter 2: $\quad$ Background and Related Research $\quad 3$

2.1 Fission yeast Schizosaccharomyces pombe . . . . . . . . . . . . . 3

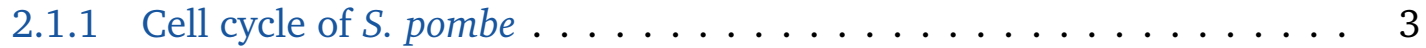

2.1.2 S. pombe as a model organism $\ldots \ldots \ldots \ldots$

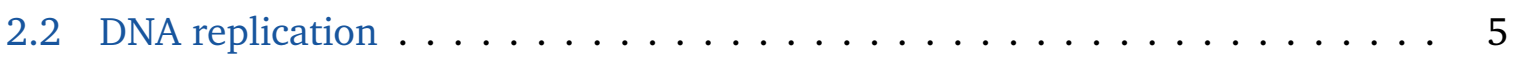

2.3 Replication stress in $S$ pombe . . . . . . . . . . . . . . 6

2.3.1 Replication stress and its impediments ............. 6 


\section{Contents}

2.3.2 Hydroxyurea $(\mathrm{HU})$ as a replication inhibitor $\ldots \ldots \ldots \ldots \ldots$

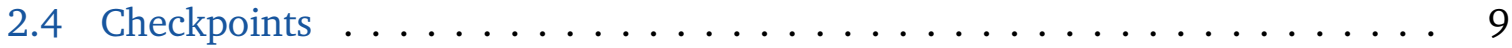

2.4.1 Replication checkpoint: a replication stress response . . . . . . . . 9

2.4 .2 DNA damage checkpoint . . . . . . . . . . . . . 12

2.5 Environmental stress responses . . . . . . . . . . . . . . . 15

2.6 The interplay between Core Environmental Stress Response (CESR), Stress Activated Protein Kinase (SAPK) pathway, and replication stress response . . 17

2.7 Hypothesis . . . . . . . . . . . . . . . . . . . . . . . . . . . 19

2.8 Specific aims . . . . . . . . . . . . . . . . . . . 19

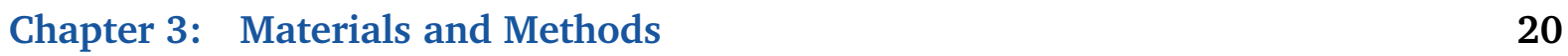

3.1 Yeast strains and growth media $\ldots \ldots \ldots \ldots \ldots \ldots$

3.2 Relative cell viability . . . . . . . . . . . . . . . . . . . 21

3.2.1 Relative viability assay . . . . . . . . . . . . . . 21

3.2 .2 Heat-shock treatment . . . . . . . . . . . . . . . 22

3.2.3 Nitrogen deprivation treatment . . . . . . . . . . . . . 22

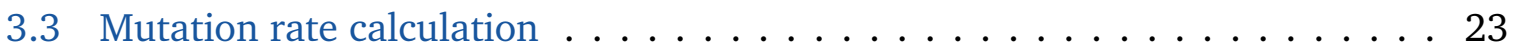

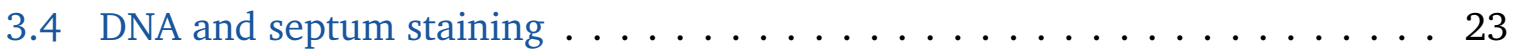

3.5 Development of diploid standard for flow cytometry . . . . . . . . . . . 24

3.6 Flow cytometry . . . . . . . . . . . . . . . . 24

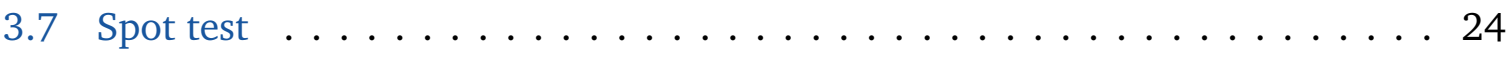

$\begin{array}{ll}\text { Chapter 4: } & \text { Results } \\ \end{array}$

4.1 Replication checkpoint mutants survive in HU following transient environ-

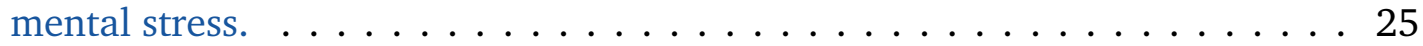




\section{Contents}

4.2 Cell-cycle progression and replication patterns in $\mathrm{HU}$. . . . . . . . . . . 27

4.3 Reciprocal shift effect of heat-shock and HU on survival . . . . . . . . . 30

4.4 Effect of heat-shock incubation time on survival $\ldots \ldots \ldots$. . . . . . . 32

4.5 Effect of heat-shock release on survival . . . . . . . . . . . . . . 34

4.6 Effect of transient environmental stress on cell morphology . . . . . . . . . . 38

4.7 DNA mis-segregation in surviving cells . . . . . . . . . . . . . . 40

4.8 Mutation rate in surviving cells . . . . . . . . . . . . . . . . 41

4.9 Cell survival using another replication inhibitor, aphidicolin (APH) . . . . . 43

$\begin{array}{ll}\text { Chapter 5: } & \text { Discussion }\end{array}$

5.1 Pre-environmental stress alters mutant viability in $\mathrm{HU}$. . . . . . . . . . . 46

5.2 Temperature protects cells from future replication stress $\ldots . . \ldots$. . . . 48

5.3 Altered DNA mis-segregation and mutation rates in mutants . . . . . . . 50

5.4 Alternative drug that may cause a similar effect: aphidicolin (APH) . . . . . 51

Chapter 6: Conclusions and Future Work $\quad 53$

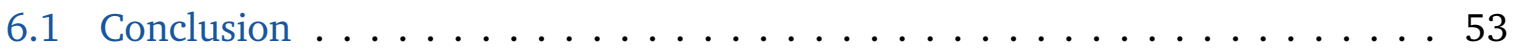

6.2 Model . . . . . . . . . . . . . . . . . . . . . . . . . 54

6.3 Future Work . . . . . . . . . . . . . . . . . . . 55

Appendix A: Effect of Nitrogen deprivation on cell survival $\quad 57$

$\begin{array}{ll}\text { References } & 60\end{array}$ 


\section{List of Tables}

2.1 Homologues of proteins involved in replication checkpoint and DNA damage checkpoint. ............................. 14

3.1 S. pombe strains used in this study. . . . . . . . . . . . . . . 21 


\section{List of Figures}

2.1 Life cycle of Schizosaccharomyces pombe . . . . . . . . . . . . . . 4

2.2 Replication structure in $S$. pombe $\ldots \ldots \ldots \ldots \ldots \ldots \ldots$

$2.3 \mathrm{HU}$ induced replication stress in $S$. pombe $\ldots \ldots \ldots \ldots \ldots \ldots$

2.4 Replication structure in $\mathrm{HU}$ in S. pombe . . . . . . . . . . . . . . 10

2.5 Replication checkpoint mutant viabilities in $\mathrm{HU} \ldots \ldots \ldots \ldots$

2.6 Components of DNA replication and damage checkpoint pathway in S. pombe. 13

2.7 SAPK signalling network in S. pombe . . . . . . . . . . . . . . . 16

2.8 Replication checkpoint mutant survival in envrionmental stress + HU . . . . 18

4.1 Pre-exposure to environmental stress improves replication checkpoint mutant viability in $\mathrm{HU} . \ldots \ldots \ldots \ldots \ldots \ldots \ldots \ldots$

4.2 Effect of transient heat shock on cell-cycle kinetics. . . . . . . . . . . 28

4.3 Exposure to concomitant HU and heat-shock produces a suspected G2 arrest. 31

4.4 Heat shock incubation time directly influences survival. . . . . . . . . . 33

4.5 Cells viability remains constant for long period after heat shock. . . . . . . . 35

4.6 Cell cycle dynamics in HU with different resting periods. . . . . . . . . . . 36

4.7 DNA synthesis progression in HU with different resting periods. . . . . . . 37

4.8 Consequences of Survival Post-Temperature. . . . . . . . . . . . . . . . . 39

4.9 DNA mis-segregation in HU. . . . . . . . . . . . . . . . 41 


\section{List of Figures}

4.10 DNA mutation in HU. . . . . . . . . . . . . . . . . . . . . 42

4.11 Cell viability in replication inhibitor HU or aphidicolin. . . . . . . . . . . . 44

6.1 Contribution of environmental stress response pathways in adaptation to replication stress $\ldots \ldots \ldots \ldots \ldots \ldots \ldots \ldots$

A.1 Effect of transient nitrogen deprivation on cell-cycle kinetics. . . . . . . . . 58

A.2 Consequences of Survival in nitrogen deprivation + HU. . . . . . . . . . . . 59

A.3 DNA mis-segregation in nitrogen deprivation + HU survival. . . . . . . . . 59 


\section{List of Abbreviations}

$\begin{array}{ll}\text { 9-1-1 } & \text { Rad9-Hus1-Rad1 } \\ \text { cut } & \text { Cell untimely torn } \\ \text { S. cerevisiae } & \text { Saccharomyces cerevisiae } \\ \text { S. pombe } & \text { Schizosaccharomyces pombe } \\ \text { AB } & \text { Aniline blue } \\ \text { APH } & \text { Aphidicolin } \\ \text { Atf1 } & \text { Activating transcription factor - 1 } \\ \text { CAN } & \text { Canavanine } \\ \text { CDK } & \text { Cyclin-dependent kinase } \\ \text { DAPI } & \text { Core environmental stress response } \\ \text { CESR } & \text { Checkpoint kinase 1 } \\ & \\ \text { Chk1 } & \text { 4-diazabicyclo[2.2.2]octane } \\ & \end{array}$


List of Figures

$\begin{array}{ll}\text { DNA } & \text { Deoxyribonucleic acid } \\ \text { dNTP } & \text { Deoxyribonucleoside 5'-triphosphates } \\ \text { DSB } & \text { Double stranded break } \\ \text { EMM } & \text { Edinburgh minimal medium } \\ \text { EMM-N } & \text { EMM without nitrogen } \\ \text { FALCOR } & \text { Fluctuation anaLysis calculatOR } \\ \text { FPC } & \text { Fork protection complex } \\ \text { G1 phase } & \text { Gap 1 phase } \\ \text { G2 phase } & \text { Gap 2 phase } \\ \text { Hsp } & \text { Heat-shock protein } \\ \text { HU } & \text { Hydroxyurea } \\ \text { M phase } & \text { Mitosis phase } \\ \text { MAPK } & \text { Mitogen-activated protein kinase } \\ \text { MCM } & \text { Minichromosome maintenance protein complex } \\ \text { MRN } & \text { Mre11-Rad50-Nbs1 } \\ \text { MCM } & \text { Ma-Sandri-Sarkar Maximum Likelihood Estimator } \\ \text { NAcleoside diphosphate kinase }\end{array}$


List of Figures

$\mathrm{NH} 4 \mathrm{Cl} \quad$ Ammonium chloride

PMG Pombe minimal glutamate

RFC DNA replication factor C complex

RNR Ribonucleotide reductase

RPA Replication protein A

S phase DNA synthesis phase

SAPK Stress-activated protein kinase

SI Septation Index

SLC Solute carrier

ssDNA Single stranded DNA

TOR Target of Rapamycin

TORC1 Target of rapamycin complex - 1

TORC2 Target of rapamycin complex - 2

YES Yeast extract with supplements 


\section{Chapter 1}

\section{Introduction}

\subsection{Overview of Thesis}

Faithful DNA replication is important to the fitness of daughter cells and their growth. However, interruptions in replication can occur due to some internal and external factors. Hydroxyurea (HU) is a well-studied drug that slows replication fork progression and causes replication stress. From previous studies, we know that replication stress can result in DNA damage, mutation, chromosome rearrangements and various human diseases such as cancer $[1,2]$. To prevent these consequences, the replication checkpoint factors promote replication arrest by stabilizing interrupted replication. This checkpoint pauses the cell cycle in S-phase and gives the cell time to recover and repair DNA. It is well known that the checkpoint competent cells die in HU following replication instability. We consider the role of cellular environment in response to replication stress and aim to define the effect of transient environmental stress on cell survival during replication stress. We used fission yeast Schizosaccharomyces pombe and replication inhibitor HU to study the heat-shock and nitrogen depletion effect on replication checkpoint mutants 


\section{Introduction}

$(\operatorname{rad} 3 \Delta, \operatorname{mrc1} \Delta, c d s 1 \Delta)$. We demonstrate that the pre-exposure to heat-shock or nitrogen starvation improves survival in replication checkpoint mutants in HU by inducing a survival effect within the cell. We found that this enhanced survival is accompanied by the change in DNA mutation and abnormal segregation. We also attempt to test this enhanced survival effect using alternate replication inhibitor, aphidicolin. The data obtained from this can be applied for disease treatment such as cancer. Furthermore, there has long been a global problem of survival in environmental changes such as climate change, and the proposed work could certainly be used as an innovative solution to this challenge.

\subsection{Thesis Organization}

This thesis comprises six chapters. Chapter 2 gives brief background about fission yeast and its checkpoints and highlights some important findings in related field. Chapter 3 provides detailed methods used in this study and the results are depicted in Chapter 4. Chapter 5 discusses and concludes the study. Chapter 6 summarizes the thesis and discusses proposed directions and possible approaches. 


\section{Chapter 2}

\section{Background and Related Research}

In this chapter, we discuss the replication checkpoint in fission yeast to understand the stress response. This chapter also touches on related work of environmental stress response pathway, which is important to review as our goal is to define the environmental effect on cell during replication stress.

\subsection{Fission yeast Schizosaccharomyces pombe}

The fission yeast Schizosaccharomyces pombe (S. pombe) is a unicellular archaeascomycete fungus which was diverged from budding yeast Saccharomyces cerevisiae approximately 600 million years ago [3]. It is rod-shaped, 7-14 $\mu \mathrm{m}$ long and 4 $\mu \mathrm{m}$ wide. It reproduces by medial fission and grows in length instead of width.

\subsubsection{Cell cycle of $S$. pombe}

The cell cycle of S. pombe is comprised of four distinct phase; G1 (gap 1), S (DNA synthesis), G2 (gap 2) and M (mitosis). After nuclear division in M phase, the binucleated 


\section{Background and Related Research}

cells enter into G1 and S phase, where a septum that divides the cell into two separate daughter cells is formed. After cell division, the newly born daughter cells spend 70\% of the time in G2 phase where they increase in biomass. Since the cell length is highly regulated throughout their life cycle, it is a great indicator of cell cycle stages. The total length of the cell cycle is between 2.5 and 4 hours. Unlike S. cerevisiae, the S. pombe life cycle is mainly haploid. However, cells enter a transient quiescent (G0) state or a diploid vegetative cycle upon nitrogen starvation, and produce zigzag or banana-shaped asci by conjugating with a partner of the opposite mating type (refer to Figure 2.1).

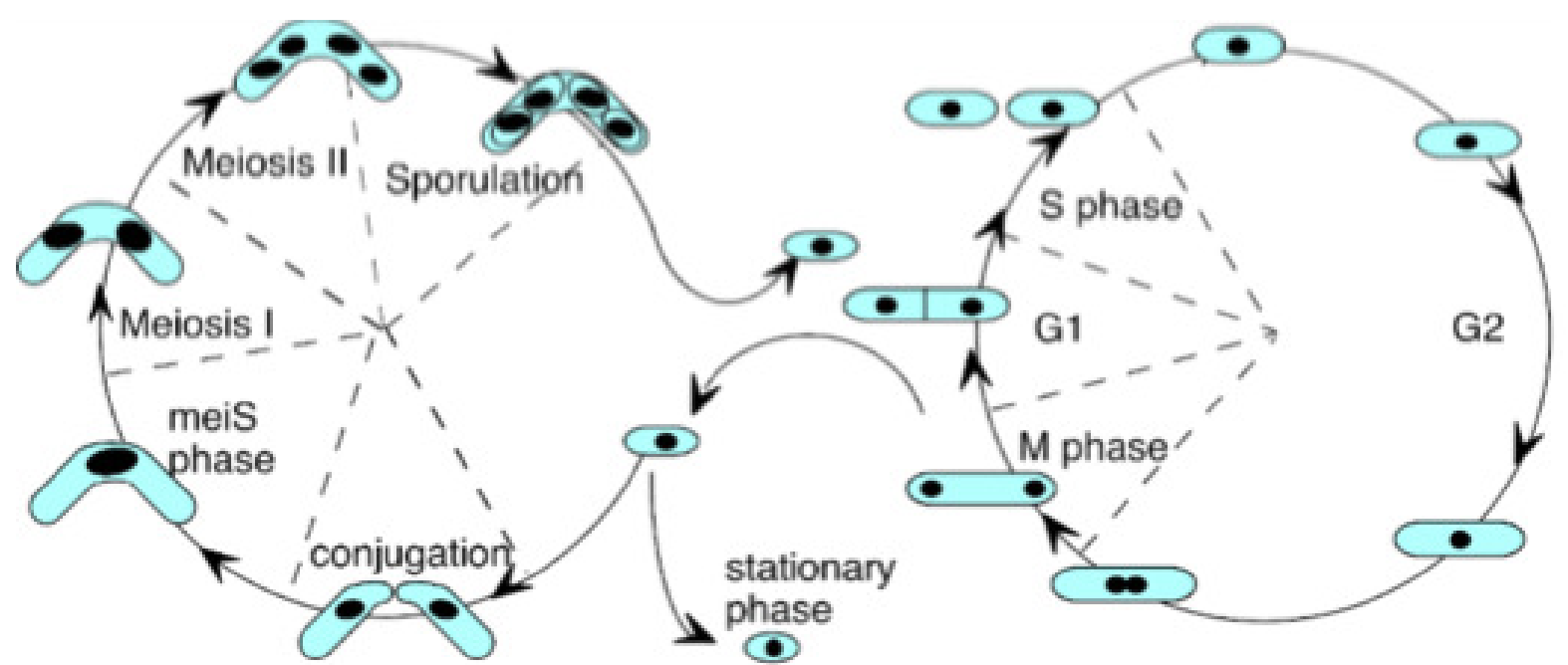

\section{Meiotic cells}

\section{Vegetative cells}

Fig. 2.1 Life cycle of Schizosaccharomyces pombe. The diploid vegetative or mitotic cycle is on the right. The cell cycle divides into G1 (10\%), S (10\%), G2 (70\%), and M (10\%) phase. Cell division occurs with the formation of a septum in late G1 to early S phase, and new daughter cells enter G2 phase where they increases in size before entering M phase for nuclear division. Cells follow transient meiotic cell cycle (on the left) in the presence of an opposite mating-type partner upon nitrogen starvation (figure is taken from [4]). 


\section{Background and Related Research}

\subsubsection{S. pombe as a model organism}

S. pombe shares many features with cells of more complicated eukaryotes [5]. Its genome is $13.8 \mathrm{Mb}$ in three chromosomes; chromosome I (5.7 Mb), II (4.6 Mb) and III (3.5 Mb), making it an easily manipulated unicellulcar model organism. Its complex centromeres and replication origins is an advantage to study human chromosomes in an inexpensive and rapidly grown research model. Due to its short life cycle compared to mammalian cell line, it is an ideal model organism for cell-cycle investigation. In addition, discoveries in DNA replication and damage checkpoint proteins, having homologues in human, make it a good model organism of choice in our project to understand cell cycle stages and checkpoint activation. In contrast to budding yeast, fission yeast is sensitive to significant lower doses of the replication inhibitor hydroxyurea (HU), enhancing its appeal as a proposed model organism.

\subsection{DNA replication}

DNA needs to be duplicated in S phase before cells undergo nuclear division in $\mathrm{M}$ phase, so both daughter cells receive same amount of genetic information. The process of duplicating DNA is called DNA synthesis or DNA replication, which is conserved in yeasts to mammals. Replication process begins with the unwinding of DNA by a conserved helicase MCM (minichromosome maintenance protein complex), and the area where two strands of DNA are separated is termed as DNA replication fork. The progression of helicase generates single stranded DNA (ssDNA), which is coated with replication protein A (RPA), a single stranded binding protein in order to avoid rewinding. DNA polymerases pol $\epsilon$ on leading-strand, and pol $\delta \& \operatorname{pol} \alpha$ on lagging-strand, read the ssDNA template and 


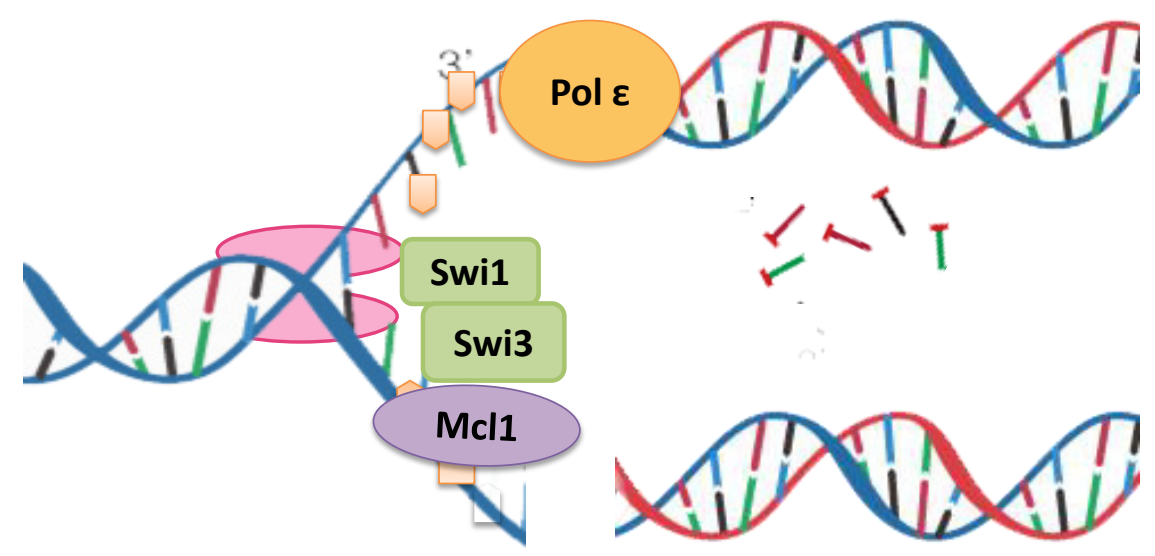

Fig. 2.2 Replication structure in S. pombe. Replication is facilitated by the replication fork proteins shown. Unwinding of DNA by helicase causes ssDNA which is the substrate of polymerases. The activity of helicase and polymerases is coordinated by fork protection complex (FPC) which includes the components Swi1, Swi3, Mrc1 and Mcl1.

synthesize new DNA by utilizing free dNTPs (deoxyribonucleoside 5'-triphosphates) (refer to Figure 2.2). The replication fork protection complex (FPC) connects helicase and polymerases to maintain the replication fidelity [6]. In fission yeast, the FPC components include Swi1, Swi3, Mcl1 and Mrc1. As a result of the coordination between fork proteins, when polymerases are arrested in slow zones, helicase also slows down to avoid producing more ssDNA; and thus regulating replication fork processivity $[6,7,8]$.

\subsection{Replication stress in S. pombe}

\subsubsection{Replication stress and its impediments}

Replication process occurs rapidly, occupying 20 to 30 minutes of the $3 \mathrm{~h}$ fission yeast cell cycle [6]. During this period, replication fork progression may be hindered by various internal and external factors including excessive origin firing, depletion of 


\section{Background and Related Research}

nucleotides, reduced replication machinery, conflicts between transcription and replication, or replication inhibitory drugs (e.g. hydroxyurea) (reviewed in [1, 2]). Disrupting DNA replication causes fork slowing or stalling, a symptom of replication stress. Failure to resolve replication stress during S-phase promotes DNA damage, mutation, chromosome rearrangements, genome instability and may contribute to various human diseases $[1,7,9]$.

\subsubsection{Hydroxyurea (HU) as a replication inhibitor}

Hydroxyurea (HU, also called hydroxycarbamide) has been used as a DNA replication inhibitor and S-phase synchronizing agent in eukaryotes. HU enters into cells via passive diffusion [10], although a recent work suggests that solute carrier (SLC) transporters are also required for HU cellular uptake [11]. Once inside the cell, HU inhibits the enzyme ribonucleotide reductase (RNR) $[12,13]$. RNR converts ribonucleoside diphosphates into their corresponding deoxyribonucleotides which undergo phosphorylation by nucleoside diphosphate kinase (NDK), and are used by DNA polymerases in S-phase for the synthesis of new DNA $[13,14]$. The RNR enzymatic reaction is catalyzed by tyrosyl free radicals [12]. HU targets RNR by scavenging tyrosyl free radicals, lowering enzymatic activity, decreasing nucleoside diphosphates (NDPs), and ultimately decreasing dNTP levels $[13,15,16,17]$. The exact mechanism of HU foraging tyrosyl free radicals is unknown [18]. 
2 Background and Related Research 


\subsection{Checkpoints}

Checkpoints arrest the cell cycle if conditions are unfavourable for growth, allowing the cell time to repair. Once the problem is resolved, checkpoint proteins are inactivated and cells enter the next cell cycle stage. The checkpoint pathways play an important role in DNA integrity and genome stability. Each cell cycle stage has its own checkpoint pathway; intra-S phase and DNA replication checkpoints in S-phase, DNA damage checkpoint in G2 phase, spindle assembly checkpoint in M phase and G1/S checkpoint in G1 phase.

\subsubsection{Replication checkpoint: a replication stress response}

DNA replication forks are at risk for structural collapse or permanent inactivation when arrested by one of the impediments mentioned above. Aberrant replication fork structure may cause replication instability, which can lead to DNA damage, mutation or cell death $[19,20]$. Replication checkpoint stabilizes fork structure and prevents replication instability and its associated consequences to occur. As shown in Figure 2.4, generation of excessive ssDNA upon HU treatment in $S$. pombe provokes the activation of a group of replication checkpoint proteins in a kinase cascade [9]. The apical protein of this cascade is Rad3, which participates in both DNA damage and replication stress responses [21]. RPA coated ssDNA recruits the Rad17-RFC complex and Rad9-Hus1-Rad1 (9-1-1) clamp to the stalled fork [6, 8, 22, 23]. Activated 9-1-1 transduces the signal of stalled fork to the upstream kinase Rad3, initiating checkpoint kinase cascade $[6,8]$. Rad3 interacts with Mrc1, which acts as a mediator to recruit Cds1 to the stalled fork. Cds1 is then activated by Rad3 [24, 25, 26, 27$]$. 
2 Background and Related Research 
A)

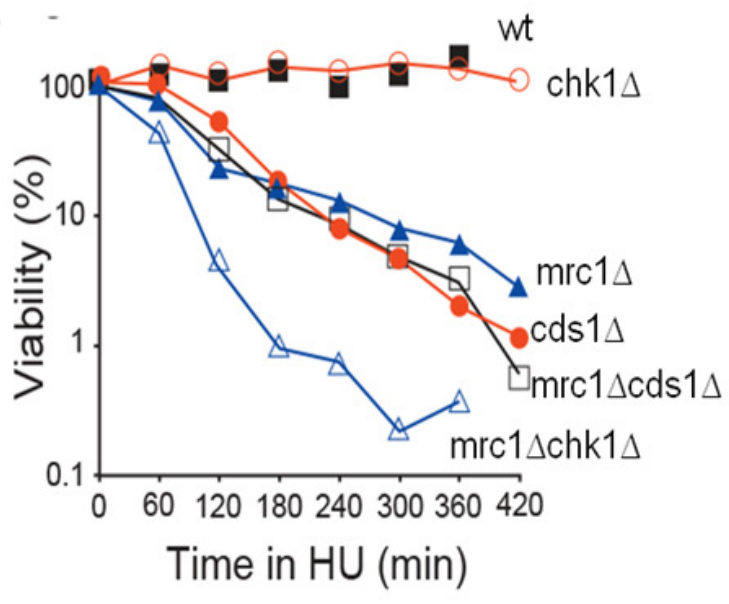

(Alcasabas et al., 2001)
B)

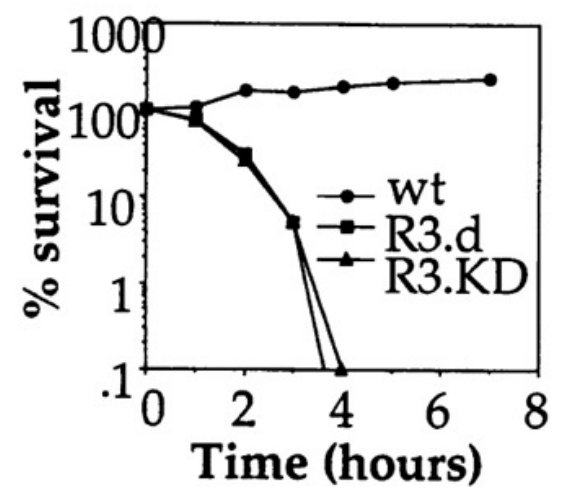

(Bentley et al., 1996)

Fig. 2.5 Replication checkpoint mutant viabilities in HU. A) $c d s 1 \Delta$ and $m r c 1 \Delta$ die in HU whereas wildtype and $\operatorname{chk} 1 \Delta$ having functional replication checkpoint protein survive under replication stress. B) Viability of wildtype and two different rad3 $\Delta$ (R3.d and R3.KD) over the time in HU. (Refer to [21] for information regarding rad3 deletion)

Previous studies showed that cells lacking replication checkpoint proteins (e.g. $\operatorname{rad} 3 \Delta, \operatorname{cds} 1 \Delta$ and $\operatorname{mrc1} \Delta$, swiftly die in HU (Figure 2.5) [21, 24, 26, 27]. Unlike wild type cells, these checkpoint mutants attempt DNA replication in HU despite decreased dNTPs. As a result, the rate of DNA synthesis is decreased while ssDNA production is increased, which is sensitive to DNA damage. The cell cycle is not paused in replication checkpoint mutants, causing them to enter M-phase with defectively replicated DNA and ultimately die [32]. However, the exact mechanism(s) of cell death in HU is unknown $[18]$. 


\section{Background and Related Research}

\subsubsection{DNA damage checkpoint}

Fork instability and ssDNA accumulation in replication checkpoint mutants in HU causes DNA double stranded break (DSB) formation. This activates the DNA damage checkpoint, sometimes also called G2-M checkpoint, which is distinct from the replication checkpoint pathway. When DSBs occur, ssDNA is generated at the breakage point. This ssDNA is recognized by the Mre11-Rad50-Nbs1 (MRN) complex which signals to upstream kinase Rad3 in fission yeast, to phophorylate downstream kinase Chk1 $[33,34]$. For the damage checkpoint, the mediator is Crb2, which recruits Chk1 for activation. Once phosphorylated, Chk1 arrests cells in G2-phase, giving time to repair DSBs before progressing towards nuclear division in M phase (Figure 2.6) [35].

DNA replication and damage checkpoint pathways are conserved in yeast and human. The overall pathways in fission yeast are shown in Figure 2.6. The homologues of the checkpoint proteins in S. cerevisiae and human are depicted in Table 2.1. 
2 Background and Related Research 
2 Background and Related Research

Table 2.1 Homologues of proteins involved in replication checkpoint and DNA damage checkpoint.

\begin{tabular}{l|l|l|l} 
& S. pombe & S. cerevisiae & Human \\
\hline Upstream kinase & Rad3 & Mec1 & ATR \\
Mediator & Mrc1 & Mrc1 & CLASPIN \\
& Crb2 & Rad9 & 53BP1 \\
Downstream kinase & Cds1 & Rad53 & CHK1 \\
& Chk1 & Rad53 & CHK2 \\
Sensors & Rad17 & Rad24 & RAD17 \\
& Rad9-Hus1-Rad1 & Ddc1-Rad17-Rad24 & RAD9-HUS1-RAD1 \\
& Mre11-Rad50-Nbs1 & Mre11-Rad50-Xrs2 & MRE11-RAD50-NBS1 \\
CDK & Cdc2 & Cdc28 & CDK1, CDK54 \\
CDK activator & Cdc25 & Mih1 & CDC25B, CDC25C \\
CDK inhibitor & Wee1, Mik1 & Swe1 & WEE1, MYT1
\end{tabular}




\section{Background and Related Research}

\subsection{Environmental stress responses}

To maintain cell viability in response to environmental variations, the regulation of cell cycle progression and hence the regulation of growth is critical for all organisms. Signaling pathways sense extracellular changes and enable cells to adapt to the adverse conditions to survive. The stress-activated protein kinases (SAPKs), members of an MAP kinase (MAPK) subfamily, are the key regulators of transcriptional response to a variety of stresses, which are non-genotoxic. In S. pombe, Sty1 (also known as Spc1) is a core element of this pathway that stimulates transcription by phosphorylating the Atf1 transcription factor in response to various environmental stimuli $[36,37]$. Phosphorylated Atf1 binds to protein Pcr1 as a heterodimer, which regulates target gene transcription $[36,37]$. A study reported reduced cell viability during nutrient deprivation in S. pombe cells lacking Atf1 and demonstrated the importance of SAPK pathway [37]. Previous studies showed that osmotic stress and oxidative stress induce Sty1 activity via Wis1 whereas heat-shock triggers the activation of Sty1 by inhibiting Pyp1/2, and not by activating Wis1 $[38,39]$. These results suggest there are two independent pathways that transmit environmental stress signals to Sty1. These regulatory pathways also involve other components, not necessarily active in all types of stress responses and their exact role(s) still needs to be determined. The overall SAPK pathway is shown in Figure 2.7. This pathway is conserved in yeast and human and the orthologs to key components of this pathway in humans are p38-MAPK (Sty1) and ATF-2 (Atf1). 
2 Background and Related Research 
2 Background and Related Research

TORC2 also responds to a variety of stresses including osmotic, oxidative, and temperature stress in order to control cell cycle progression in adverse condition $[41,42,43]$.

\subsection{The interplay between Core Environmental Stress Response (CESR), Stress Activated Protein Kinase (SAPK) pathway, and replication stress response}

Core environmental stress response (CESR) genes are transcriptionally up-regulated in response to most environmental stresses such as heat shock, osmotic stress, oxidative stress and genotoxic stess $[44,45]$. Induced CESR genes encode proteins that are involved in a variety of functions including cell cycle regulation, signal transduction and transcriptional regulation. A genome-wide study of transcriptional changes in fission and budding yeast by the Bahler group (2003) confirmed that the up-regulation of majority of CESR gene is dependent on Sty1 activation in most stresses [44]. This includes, but is not limited to, the over-expression of Hsp16 and Hsp9 through Sty1, causing cell cycle arrest and DNA repair in response to several environmental stimuli including heat-shock [44]. A previous study showed that Hsp16 gene expression was activated during HU induced nucleotide starvation in a Sty1-MAPK dependent manner [39], suggesting a role of SAPK in response to replication stress. Watson et al. noticed the induction of certain stress response genes in response to ionizing radiation (IR) in $S$. pombe wildtype cells and at some extent in $\operatorname{rad} 3 \Delta$ or sty $1 \Delta$ single mutants [46]. On the other hand, a rad $3 \Delta$ sty $1 \Delta$ double mutant was not able to activate gene expression under IR [46]. This research indicates the possibility of 


\section{Background and Related Research}

combined action of Rad3 and Sty1 during IR. Apart from this, subsequent studies reported the replication checkpoint dependent transcriptional regulation of CESR genes in response to replication stress in S.pombe [45, 47]. In line with this, studies in budding yeast and mammals showed transcriptional regulation in response to replication stress, suggesting the conserved transcriptional response from yeast to human [47]. Collectively, these findings suggest that molecular crosstalk exists between environmental stress signaling and the DNA replication checkpoint pathway. However, the exact mechanism of this communication is unknown. 


\section{Background and Related Research}

$12 \mathrm{mM} H U$, cell survival is significantly increased. Similarly, mutants exposed to temperature stress and then HU treatment survive better than mutants maintained at normal temperature in $\mathrm{HU}$ (data not published, Sabatinos communication Figure 2.8).

\subsection{Hypothesis}

It is unclear whether replication checkpoint mutant survival in HU after heat-shock or nitrogen depletion is due to the environment. Further, the effect of the environment on HU survival is not defined. We hypothesize that environmental stress pre-conditions cells to maintain viability in future replication stress. The main goal is to measure the effect of environmental stress on cell survival and to find the mechanism(s) of increased viability.

\subsection{Specific aims}

- Determine whether pre-exposure to environmental stresses pre-conditions mutants to future HU exposure.

- Assess the effect of prior heat-shock on surviving cells.

- Examine how environmental stress promotes mutant survival in HU. 


\section{Chapter 3}

\section{Materials and Methods}

In this chapter, we describe the experimental setup to answer the research questions and provide details on methods used.

\subsection{Yeast strains and growth media}

All fission yeast strains used in the proposed research are listed in Table 3.1, and are gifts of Susan Forsburg (University of Southern California, Los Angeles, CA USA). Unless otherwise stated, all strains were grown in yeast extract with supplements (YES) medium, a rich yeast extract based medium, at $30^{\circ} \mathrm{C}$. 
Table 3.1 S. pombe strains used in this study.

\begin{tabular}{|c|c|}
\hline Strain No. & Genotye \\
\hline FY3454 & $h^{+}$ura4-D18 ade6-M210 \\
\hline FY2317 & $\begin{array}{l}h^{+} \text {leu1-32::hENT1-leu1 }{ }^{+}(p J A H 29) \text { his7-366::hsv-tk-his } 7^{+}(p J A H 31) \\
\text { ura4-D18 ade6-M210 }\end{array}$ \\
\hline FY3179 & $\begin{array}{l}h^{+} \text {mrc1 }:: \text { ura4 } 4^{+} \text {leu1-32::hENT1-leu1 }{ }^{+} \text {(pJAH29)his7-366::hsv-tk } \\
\text {-his7 } 7^{+} \text {(pJAH31) ura4-D18 ade6-M210 }\end{array}$ \\
\hline FY5148 & $\begin{array}{l}h^{+} \text {cds1 } 1:: u r a 4^{+} \text {leu1-32::hENT1-leu1 }{ }^{+} \text {(pJAH29)his7-366::hsv-tk } \\
- \text { his7 }^{+} \text {(pJAH31) ura4-D18 ade6-M210 }\end{array}$ \\
\hline FY5149 & $\begin{array}{l}h^{+} \text {chk1 } 1:: \text { ura4 }^{+} \text {leu1-32::hENT1-leu1 }{ }^{+} \text {(pJAH29)his7-366::hsv-tk } \\
-h i s 7^{+}(\text {pJAH31) ura4-D18 ade-704 }\end{array}$ \\
\hline FY5150 & $\begin{array}{l}h^{+} \text {rad3A::ura4 }{ }^{+} \text {leu1-32::hENT1-leu1 }{ }^{+} \text {(pJAH29)his7-366::hsv-tk } \\
- \text { his } 7^{+}(\text {pJAH31) ura4-D18 ade6-M210 }\end{array}$ \\
\hline FY435 & $h^{+}$ura4-D18 ade6-M210 leu1-32 his7-366 \\
\hline FY436 & $h^{-}$ura4-D18 ade6-M216 leu1-32 his7-366 \\
\hline
\end{tabular}

\subsection{Relative cell viability}

\subsubsection{Relative viability assay}

Cells were grown in EMM media with supplements $(225 \mathrm{mg} / \mathrm{L}$ uracil and adenine, $5 \mathrm{~g} / \mathrm{L} \mathrm{NH} 4 \mathrm{Cl}$ ) at $30^{\circ} \mathrm{C}, 200 \mathrm{rpm}$ to early log phase. For viability experiments, 12mM HU was added to cultures at O.D.600 between 0.3 and 0.6. Immediately after HU addition, $20 \mu \mathrm{L}$ of culture was sampled and diluted to $1: 1000$, and then $30 \mu \mathrm{L}$ of diluted 
culture was spread on YES plate. This was noted as the 0 hour time-point $(t=0)$ for viability testing. Similar steps were performed at 2, 4 and 6 hours after adding HU. Simultaneously, cells were fixed in $70 \%$ ethanol at each time point for future analysis with microscopy and flow cytometry. Ethanol fixed cells were stored at $4^{\circ} \mathrm{C}$ for further analysis. YES plates were incubated at $30^{\circ} \mathrm{C}$ for $2-3$ days and colonies on were enumerated. The percent viable cells were determined by comparing with $t=0$ counts to examine the survival.

\subsubsection{Heat-shock treatment}

Wildtype and mutants were grown as mentioned above in EMM media containing supplements. Overnight grown cultures (O.D. ${ }_{600}=0.3-0.6$ ) were transferred to $40^{\circ} \mathrm{C}$ in a shaking water-bath for 2.5 hour incubation. The temperature was then decreased to optimal growth temperature $\left(30^{\circ} \mathrm{C}\right)$ and $12 \mathrm{mM} \mathrm{HU}$ was added. Relative viability was performed as described in Chapter 3.2.1.

\subsubsection{Nitrogen deprivation treatment}

For nitrogen starvation, logarithmically grown cells in EMM media were washed twice in sterile distilled water, resuspended in starvation media lacking nitrogen (EMM-N with $75 \mu \mathrm{g} / \mathrm{mL}$ supplements), and incubated at $25^{\circ} \mathrm{C}$ for $16-18$ hours. Starved cells were re-fed by adding EMM with supplements and incubated at $30^{\circ} \mathrm{C}$ for 30 mins, before adding HU. Viability assay was then performed under $12 \mathrm{mM} \mathrm{HU}$. 


\subsection{Mutation rate calculation}

Mutation rate was measured using canavanine (CAN) mutation screening. All strains were grown to early log phase in $\mathrm{EMM}$ at $30^{\circ} \mathrm{C}$ while shaking. $\mathrm{HU}(12 \mathrm{mM})$ was added to the cultures and a $500 \mu \mathrm{L}$ aliquot was immediately withdrawn. Two steps were performed using the aliquot; i) cells were spread onto 15-cm PMG (pombe minimal medium with glutamate) plate containing $70 \mu \mathrm{g} / \mathrm{ml}$ canavanine. The plates were stored at $30^{\circ} \mathrm{C}$ for $8-10$ days, ii) sample was diluted to 1:1000 and plated on YES media and the plates were incubated at $30^{\circ} \mathrm{C}$ for $2-3$ days. Colonies were counted and mutation rate was calculated using Ma-Sandri-Sarkar Maximum Likelihood Estimator (MSS-MLE) method and Fluctuation AnaLysis CalculatOR (FALCOR) calculator [48].

\subsection{DNA and septum staining}

Ethanol fixed cells were washed with water. Pellets were incubated with $3 \%$ aniline blue at room temperature for 15 mins to stain septa. After incubation, the sample was spun down and supernatant was removed carefully without disturbing pellets. The pellet was then smeared onto a microscopy glass slide. For DNA staining, $5 \mu \mathrm{L}$ DAPI containing DEBCO mount media was placed onto the smear and covered with a coverslip. Slides were stored indefinitely at $-20^{\circ} \mathrm{C}$. Images were taken under microscope with UV excitation source, and cells were counted using ImageJ. The detailed protocol is described in [49]. 


\subsection{Development of diploid standard for flow cytometry}

A small patch of one strain was smeared onto an ELN plate and another patch of the opposite mating type strain was smeared alongside the first. Both were mixed with 10 $\mu \mathrm{L}$ of water, allowed to dry and incubate at room temperature overnight. Half of the patch was then retrieved on EMM lacking adenine after $16 \mathrm{hr}$ incubation, and another half was retrieved after $24 \mathrm{hr}$ and incubated at $30^{\circ} \mathrm{C}$ for 3-4 days for the formation of diploid colony. Once developed, a diploid colony was streaked and grown onto YES containing PhloxinB plate and then transferred to YES medium. For flow cytometry analysis, the diploid culture was fixed in $70 \%$ ethanol and stored at $4^{\circ} \mathrm{C}$ in refrigerator.

\subsection{Flow cytometry}

Flow cytometry was performed as described in [50]. Briefly, ethanol fixed cells were washed twice in $50 \mathrm{mM}$ sodium citrate buffer, and then incubated with $0.1 \mathrm{mg} / \mathrm{ml}$ RNase A solution at $37^{\circ} \mathrm{C}$ for 2 hour followed by a brief incubation with $1 \mu \mathrm{M}$ SYTOX green. The samples were then transferred at $4^{\circ} \mathrm{C}$ for at least 30 mins. DNA content were measured using BD Accuri C6 Plus flow cytometer and analyzed using FlowJo (TreeStar).

\subsection{Spot test}

Cells were grown in YES media to early log phase before all cultures were normalized and diluted with YES to five-fold in a 96 well plate. For HU and aphidicolin (APH) sensitivity, the diluted cultures were spotted onto YES containing no drug and YES containing $\mathrm{HU}(2 \mathrm{mM}, 5 \mathrm{mM})$ and APH $(1 \mu \mathrm{M}, 5 \mu \mathrm{M}$ and $10 \mu \mathrm{M})$ using a 48-pin pinning tool (V\&P Scientific). Dried plates were incubated for 3-4 days at $30^{\circ} \mathrm{C}$. 


\section{Chapter 4}

\section{Results}

This chapter analyzes our key experimental data that was collected by performing various experiments mentioned in Chapter 3. We describe the schematic of the experimental setup wherever possible along with the results.

\subsection{Replication checkpoint mutants survive in HU following transient environmental stress.}

Replication checkpoint mutants $\operatorname{rad} 3 \Delta, \operatorname{cds} 1 \Delta$ and $\operatorname{mrc} 1 \Delta$ cannot undergo

replication arrest in hydroxyurea (HU) and ultimately die [21, 24, 26, 27]. We confirmed the viability of $\operatorname{rad} 3 \Delta, \operatorname{cds} 1 \Delta$ and $m r c 1 \Delta$ in HU using relative viability assays. HU was added to logarithmically grown wildtype and checkpoint mutants (12 mM final concentration of $\mathrm{HU})$. Hereafter, we refer this experiment as "No stress + HU" since the cells did not experience environmental stress in addition to drug. DNA damage checkpoint mutant, $\operatorname{chk} 1 \Delta$ was included in this and all subsequent experiments as a control; since Chk1 is in the DNA damage checkpoint, chk1 $\Delta$ mutants are not affected substantially by 
4 Results 


\section{Results}

HU. In agreement with the previous studies, $\operatorname{rad} 3 \Delta, \operatorname{cds} 1 \Delta$ and $\operatorname{mrc} 1 \Delta$ died in $\mathrm{HU}$, showing less than $10 \%$ of survival rate at $t=4$ as compared to $t=0$ (Figure $4.1 \mathrm{~A}$ ). Death was not observed in wildtype or $\operatorname{chk} 1 \Delta$ (Figure 4.1A).

In order to determine the role of cellular environment in mutant survival in $\mathrm{HU}$ after transient environmental stress, we considered heat-shock treatment at $40^{\circ} \mathrm{C}$ for 2.5 $\mathrm{hr}$ and nitrogen starvation for 16-17 hr before adding HU. Henceforth, we call the former condition as "Heat-shock + HU" and the later as "Nitrogen deprivation + HU". As shown in Figure 4.1B, 4.1C, the viability in $\operatorname{rad} 3 \Delta, c d s 1 \Delta$ and $\operatorname{mrc1} \Delta$ was improved by $\sim 90 \%$ on average in heat-shock $+\mathrm{HU}$ and by $\sim 30 \%$ in nitrogen stress $+\mathrm{HU}$, compared to no stress $+\mathrm{HU}$ at $\mathrm{t}=4$. However, a slight drop in the viability trend at $\mathrm{t}=6 \mathrm{in}$ nitrogen deprivation + HU was observed (see discussion in Chapter 5). Altogether, our relative viability data showed that viability in replication checkpoint mutants are altered in $\mathrm{HU}$ when previous exposure to environmental stress is considered.

\subsection{Cell-cycle progression and replication patterns in $\mathrm{HU}$}

Since high temperature pauses G2-M transition during cell division [51, 52], there may be two possibilities for increased viability; i) cells released from temperature progress from G2 into the next cell cycle, wherein they encounter HU-dependent stress that is altered; or, ii) Cells released from temperature incubation remain in G2 even after the temperature was dropped to $30^{\circ} \mathrm{C}$. In the latter case, cells would not experience HU-dependent replication stress because they do not enter into S-phase. This might contribute to the enhanced viability in replication checkpoint mutants in HU. To test this, we used microscope imaging and counted cells with different morphological features; 
4 Results 


\section{Results}

mononucleated cells (G2-phase), bi-nucleated (G1-phase), septated (G1 to S-phase), and cells with nuclear division (M-phase). The proportion of G1/S cells, called the Septation Index (SI) [53] was $10-15 \%$ of the total cell counts in wildtype and mutants at $\mathrm{t}=0$ in no stress $+\mathrm{HU}$ (Figure $4.2 \mathrm{~A}$ ). After $2.5 \mathrm{~h}$ at $40^{\circ} \mathrm{C}$, SI was approximately $5 \%$ (Figure $4.2 \mathrm{~B}$ ). A septation peak occurred at $\mathrm{t}=2$ in heat-shock $+\mathrm{HU}$ followed by the gradual decrease in subsequent time points (Figure 4.2B). We also tested this in nitrogen stress $+\mathrm{HU}$ condition to see whether cells were released from G1 arrest upon replenishment of nitrogen source (Figure A.1A). Significant experimental variation was observed after nitrogen arrest and HU protocols (see discussion in Chapter 5), leading us to change our nitrogen starvation protocol in future work (not covered in this thesis).

We observed replication patterns during HU treatment using flow cytometry of total cellular DNA content. Cells were stained with SYTOX green, a nucleic acid stain, as described in Chapter 3. A typical, asynchronous 2C DNA content at $t=0$ was observed in all indicated strains in No stress + HU (Figure 4.2C upper panel). With addition of HU, 2 DNA peaks developed as cells shifted toward a 1C DNA content. After $4 \mathrm{~h}$ of $\mathrm{HU}$ treatment, all samples had mostly 1C content cells, indicating an early S-phase arrest. After $6 \mathrm{~h}$ in HU, DNA content appeared to shift toward 2C, indicating HU attenuation and completion of replication (Figure 4.2C upper panel). These data are consistent with previous reports $[54,55]$. Unlike no stress $+\mathrm{HU}$, a shift from $2 \mathrm{C}$ to $1 \mathrm{C}$ appeared at 4 hour in heat-shock $+\mathrm{HU}$ in all strains except $\operatorname{chk} 1 \Delta$ (Figure 4.2C lower panel). The possible reason behind the consistent DNA content in $\operatorname{chk} 1 \Delta$ could be failing to add $\mathrm{HU}$. It is worth noting that $\operatorname{mrc1} \Delta, c d s 1 \Delta$ and $\operatorname{rad} 3 \Delta$ population in heat-shock $+\mathrm{HU}(\mathrm{t}=6)$ contained three types of cells carrying $1 \mathrm{C}-2 \mathrm{C}$ intermediate, $2 \mathrm{C}$, and $2 \mathrm{C}-4 \mathrm{C}$ intermediate DNA content, which was not observed in no stress $+\mathrm{HU}$ (Figure 4.2C). This indicates the 


\section{Results}

altered replication pattern in heat-shock $+\mathrm{HU}$ compared to that in no-stress $+\mathrm{HU}$. On the other hand, nitrogen starved wildtype and mutant populations comprised of equal proportion of cells having 1C and 2C content in HU (Figure A.1B). This result is in agreement with the previous work demonstrating two types of cells in nitrogen starved populations [56].

\subsection{Reciprocal shift effect of heat-shock and HU on survival}

Transient heat-shock exposure promotes cell survival in HU but we did not know whether heat shock might alter HU survival if both were administered concurrently. To test this, we performed a reciprocal shift experiment, by increasing temperature at the same time of $\mathrm{HU}$ addition and performed relative viability assay. As expected, $\mathrm{rad} 3 \Delta$, $\operatorname{mrc} 1 \Delta$ and $\operatorname{chk} 1 \Delta$ survived throughout the treatment, holding highest viability at $\mathrm{t}=4$ (Figure 4.3A). Interestingly, a gradual decline in percent viable cells was observed in $c d s 1 \Delta$, especially at $\mathrm{t}=6$ when it was reduced by $45 \%$ compared to $\mathrm{t}=4$ (Figure $4.3 \mathrm{~A}$ ). Overall, this result indicates that temperature has a profound effect on survival in HU, but may also promote some death when administered concurrently. DNA content profiles indicated most cells contained 2C DNA throughout the treatment, suggesting a G2 arrest in all indicated strains (Figure 4.3B). However, a fluctuation in the amount of DNA was seen during the treatment; whether this is negligible or pathological is unknown (see discussion in Chapter 5). Both viability and flow cytometry data suggest that the cells experienced temperature fluctuation first and arrested in G2, preventing HU-dependent effects. 
4 Results 


\subsection{Effect of heat-shock incubation time on survival}

As cells respond to heat-shock first, we anticipate that some change(s) may have occurred in cells, or that a signal may develop under heat-shock exposure, to enhance viability in following replication stress. Therefore, we considered different exposure time to heat-shock; 30 mins, 1 hour, and 2.5 hour. HU was added after these different temperature exposures to examine this effect on viability in all strains. The schematic representation of the experiment is shown (Figure 4.4A). As shown in Figure 4.4A, $\operatorname{rad} 3 \Delta, c d s 1 \Delta$ and $\operatorname{mrc1} \Delta$ showed non-stress HU death when exposed to only 30 min of high temperature. The histogram data from flow cytometry shows that cells started shifting towards 1C DNA from 2C DNA in all strains at 2 hour time $(t=2)$ and most of the cells were towards 1C DNA in subsequent time points (Figure 4.4B upper panel); this result is comparable with our previous flow data for no stress $+\mathrm{HU}$ condition (Figure 4.2C). This indicates that half an hour of heat-shock exposure is not enough to alter viability in future replication stress. However, it is remarkable that one hour at $40^{\circ} \mathrm{C}$ increased viability two-fold in $\operatorname{rad} 3 \Delta, \operatorname{mrc1} \Delta$ and $c d s 1 \Delta$ in HU (Figure 4.4A). DNA contents in these sample showed an intense peak of $1 \mathrm{C}$ DNA at $\mathrm{t}=4$ except $\operatorname{cds} 1 \Delta$ (Figure 4.4B middle panel). Viability was significantly increased in $2.5 \mathrm{hr}$ exposure to heat-shock following HU treatment (the data for $2.5 \mathrm{hr}$ was taken from previous experiments (Figure 4.1B, 4.2C) for comparison). Overall, these results shows that the time in heat-shock is directly related to the increase in replication checkpoint mutant viability in HU. 
4 Results 


\subsection{Effect of heat-shock release on survival}

We showed that temperature effect takes time to cause survival in the mutants. Then, we predicted that the temperature effect that induces mutant survival could be transient. Therefore, we tested where this temperature effect stops by allowing cells to rest at $30^{\circ} \mathrm{C}$ for different time period after releasing from heat-shock and before adding $\mathrm{HU}$, and analyze their viability, septation index and FACS profile.

In order to see whether the temperature effect gets weaker over the time, the relative viability assay was performed considering different resting time periods; $30 \mathrm{~min}$, $1 \mathrm{hr}, 2 \mathrm{hr}$, and $5 \mathrm{hr}$. Refer to Figure 4.5 for diagrammatic explanation of the experimental set up on the right). Interestingly, the survival rate in $\operatorname{mrc1} 1 \Delta$ and $c d s 1 \Delta$ remained constant at $4 \mathrm{hr}$ in $\mathrm{HU}$ in no rest, $30 \mathrm{~min}, 1$ hour and 2 hour after release conditions (Figure 4.5 bar graph; no rest data was taken from Figure 4.1B for the comparison purpose). This pattern was fluctuating in wildtype and $\operatorname{chk} 1 \Delta$. In $\operatorname{rad} 3 \Delta$, viability was dropped by almost 50\% in 30 min rest but then remained consistent in 1 hour and 2 hour resting condition (Figure 4.5 graph and table). When this survival pattern was compared with the viability in 5 hour resting condition, the viable cells in $\operatorname{mrc} 1 \Delta, \operatorname{cds} 1 \Delta$ and $\operatorname{rad} 3 \Delta$ were reduced by $30-60 \%$. Conversely, wildtype and chk1 $\Delta$ survival was not affected by the increased resting period. This shows that mutant survival is affected for longer period after releasing from heat-shock. 
4 Results 
4 Results 


\section{Results}

suggesting the release after heat-shock. In flow cytometry data, +T-HU represents the time point when cultures released from heat-shock and kept them at normal growth temperature $\left(30^{\circ} \mathrm{C}\right)$ for indicated time period without adding $\mathrm{HU}$ (Figure 4.7). All indicated strains expressed 2C DNA content at +T-HU time, suggesting G2 arrest and they were shifted towards $1 \mathrm{C}$ content in later time points, indicating the release into cell-cycle after heat-shock (Figure 4.7). 


\subsection{Effect of transient environmental stress on cell morphology}

Previous studies have shown that HU exposure causes changes in morphology in fission yeast cells. HU causes elongation in wildtype, $\operatorname{chk} 1 \Delta, \operatorname{cds} 1 \Delta$ and $\operatorname{mrc} 1 \Delta$ strains, while rad3 $\Delta$ cells become small with a cell untimely torn (cut) phenotype $[57,58]$. The cut phenotype occurs when the septum is formed across an undivided mass of DNA (reviewed in [57]). Based on this, we asked whether previous exposure to high temperature alters cell elongation in HU. The cells at each time point during HU treatment were stained with DAPI and aniline blue $(\mathrm{AB})$ and their morphology was photographed using a microscope (Chapter 4.2). As expected, wildtype and $\operatorname{chk} 1 \Delta$ were slightly elongated at 6 hour in no stress $+\mathrm{HU}$, and longer cells were observed in $c d s 1 \Delta$ and $\operatorname{mrc} 1 \Delta$ (Figure 4.8). By contrast, $\operatorname{rad} 3 \Delta$ cells were smaller and cut phenotype was seen (Figure 4.8). Moreover, cells with unequally segregated DNA were frequently observed in rad3 $\Delta$ at $6 \mathrm{~h}$ in $\mathrm{HU}$ (no stress). These results agree with previous findings of HU effects [57, 58].

Interestingly, we noticed that all strains appear to be relatively similar lengths compared to pre-HU at $6 \mathrm{~h} \mathrm{HU}$ when they were pre-treated at high temperature or pre-starved with nitrogen (Figure 4.8, A.2). The cells appeared to become wider by 6 hour in heat-shock $+\mathrm{HU}$ condition, whereas the width was not affected in no-stress + HU. Surprisingly, cut cells were less frequent in rad3 $\Delta$ post-heat-shock $+\mathrm{HU}$. At first glance, these results suggest that surviving checkpoint mutants may be healthier under heat-shock $+\mathrm{HU}$ condition than those under HU alone, but the outcomes behind this survival are undefined. 
4 Results 


\section{Results}

\subsection{DNA mis-segregation in surviving cells}

The alterated morphologies after transient heat shock led us to measure and compare the proportion of abnormal DNA segregation in no stress $+\mathrm{HU}$, heat-shock + $\mathrm{HU}$ and nitrogen-deprivation $+\mathrm{HU}$ conditions. Abnormalities were considered cells that had DNA patterns indicating aneuploidy, multiple septation or cut phenotype. We used the aniline blue and DAPI microscope pictures and counted the abnormal cells for each time-point as a proportion of total cell number. As shown in Figure 4.9, wildtype and chk1 $\Delta$ cells had fewest abnormal nuclear morphologies during HU treatment. However, approximately $4-6 \%$ of the $\operatorname{mrc} 1 \Delta$ and $c d s 1 \Delta$ population were abnormal at the later $\mathrm{HU}$ time-points. As expected, $\operatorname{rad} 3 \Delta$ cells had the highest abnormal morphologies, with more than $50 \%$ at $4 \mathrm{~h}$ and almost $60 \%$ at $6 \mathrm{~h}$ in no stress $+\mathrm{HU}$. After transient pre-stress, we noticed that the percentage of abnormal rad3 $\Delta$ morphologies dropped to $30 \%$ or less during HU (Figure 4.9, A.3). Yet, abnormal morphologies were moderately increased in $m r c 1 \Delta$ and $c d s 1 \Delta$ in heat-shock + HU compared to no-stress + HU. 
4 Results 


\section{Results}

plate are wildtype and those that form colonies are mutated. We used this concept to determine mutation rate by performing canavanine screeening as described in [61]. We found that mutation rates increased dramatically in $\operatorname{mrc} 1 \Delta$ heat-shock $+\mathrm{HU}$, and moderately in $c d s 1 \Delta$, compared to no stress + HU (Figure 4.10). 


\section{Results}

\subsection{Cell survival using another replication inhibitor, aphidicolin (APH)}

We showed that transient heat-shock before HU treatment profoundly affects viability in replication checkpoint mutants in HU. However, we wished to determine whether this temperature effect is drug specific. For this purpose, we considered using another replication inhibitor. Aphidicolin interferes with the DNA replication process in human and budding yeast cells by inhibiting DNA polymerase $[62,63]$. We determined the growth of wildtype and mutant cells using a spot assay on $1 \mu \mathrm{M}, 5 \mu \mathrm{M}$ and $10 \mu \mathrm{M}$ aphidicolin (see Chapter 3 for detail). Growth on no-drug media and in $2 \mathrm{mM}$ or $5 \mathrm{mM}$ HU was also considered as a positive and negative control, respectively. As expected, replication checkpoint mutants were sensitive to HU (both doses, Figure 4.11). Interestingly, the viability of all strains was unaffected by the aphidicolin doses used in this study, even though these concentrations are enough to cause S-phase arrest in vitro and in human cells (Figure 4.11) [62, 63]. 
4 Results 


\section{Chapter 5}

\section{Discussion}

The Rad3-related replication checkpoint is conserved from yeast to mammals. Its activation is triggered during replication stress caused by hydroxyurea (HU). This checkpoint protects the cell from DNA damage and other consequences associated with replication stress. It has previously been reported that checkpoint deficient fission yeast cells $\operatorname{rad} 3 \Delta, \operatorname{mrc} 1 \Delta$ or $c d s 1 \Delta$ cannot arrest DNA replication during HU exposure and ultimately die due to accumulation of DNA damage $[21,24,26,27]$. Interestingly, Sabatinos noted the improved viability in these checkpoint mutants under replication stress when growth temperature or nutrient level was taken into account (data not published). However, it remained unclear whether this survival was dependent on environmental stress.

Previous studies suggested a potential role of the environmental stress response pathway SAPK in response to replication stress $[45,47]$. The activation of its key component Sty1-MAPK in fission yeast and p38-MAPK in human under replication stress by $\mathrm{HU}$ indicates a possible co-relation between the environmental stress response 


\section{Discussion}

pathway and replication checkpoint activation. These findings, along with Sabatinos' work, prompted us to consider the cellular environment while studying replication stress response in Schizosaccharomyces pombe (S. pombe). In this study, we strive to assess the effect of environmental stress on replication checkpoint mutants in HU. We proposed that pre-exposure to environmental stress triggers some intra-cellular changes to promote survival under future replication stress.

\subsection{Pre-environmental stress alters mutant viability in $\mathrm{HU}$}

Unlike wildtype cells, replication checkpoint mutants $\operatorname{mrc} 1 \Delta, c d s 1 \Delta$ and $\operatorname{rad} 3 \Delta$ are not able to arrest DNA replication [32]. These mutants enter mitosis inappropriately, resulting in death $[18,32]$. Alcasabas et al. demonstrated that viability decreases in replication checkpoint mutants during HU treatment in S. pombe and S. cerevisiae [26]. In line with this, we confirm the death of the $\operatorname{mrc1} 1 \Delta, c d s 1 \Delta$ and $\operatorname{rad} 3 \Delta$ in $S$. pombe. The survival of wildtype and the DNA damage checkpoint mutant $\operatorname{chk} 1 \Delta$ confirm their intact replication checkpoint and hence their insensitivity to HU (Figure 4.1). Elevated viability of $\operatorname{mrc} 1 \Delta, c d s 1 \Delta$ and $\operatorname{rad} 3 \Delta$ was observed in the heat-shock + HU condition, and we tested whether survival is due to a temperature effect. Upon heat-shock treatment, cells are synchronized in G2 phase and inhibited from entering into M-phase [51, 52]. Our experiments confirm that cells are arrested in G2-phase post-temperature (Figure 4.2B). However, cells re-enter the cell cycle after heat-shock release; these cells enter S-phase and experience replication stress caused by HU. Furthermore, our data suggests that fission yeast may take approximately two hours to enter into the normal cell cycle after releasing from heat-shock. Consistent with this, the DNA content profile in heat-shock + HU suggests that G2-arrested cells have a 2C DNA after heat-shock, and then release and 


\section{Discussion}

enter into early S-phase with $<2 \mathrm{C}$ DNA in HU (Figure 4.2C). Therefore, we argue that increased mutant survival is not the result of G2-arrest caused by temperature. Rather, we suggest that mutants survive $\mathrm{HU}$ after transient heat shock due to environmental stress signaling that rescues their viability.

We found this effect only if transient heat-shock occurs first followed by HU. When heat-shock and HU were administered simultaneously, consistent $2 \mathrm{C}$ content was detected in all populations throughout the incubation period with $\mathrm{HU}$ although the viability of mutants was improved (Figure 4.3). This suggests constant G2 arrest. However, a slight fluctuation in the genome content for almost 1 hour during the HU treatment indicates that cells were trying to pass through but were stuck in G2 because of heat-shock. Since $70 \%$ of the cells are in G2 phase, they possibly started experiencing the heat-shock first and hence were arrested in G2, indicating a stronger temperature effect compared to HU. This confirms that cells may have never seen $\mathrm{HU}$ in reciprocal shift and the survival in reciprocal shift might be due to the continuity of G2 arrest. Based on this result, we conclude that the cells must experience the heat-shock before HU exposure in order to adapt to the replication stress. As we do not consider HU treatment first and then heat-shock in this study, this scenario will remain an area for future investigation.

Previous studies established that removing nitrogen from media induces a G1 or G0 state in yeast (reviewed in [49]). The DNA profile following nitrogen deprivation + HU showed a population with 1C and 2C DNA containing cells in all fission yeast strains used even after addition of the nitrogen source (Figure A.1B). This pattern is similar to the pattern observed by Su and Yanagida upon nitrogen starvation [56]. They noticed that a longer nitrogen starvation increases the time to S-phase entry after nitrogen 


\section{Discussion}

replenishment. We starved cells for 16-17 hours and were unable to see prominent 2C DNA content even at 6 hour after re-feeding them with nitrogen and adding HU. This indicates that either cells have not entered into the cell cycle, or, that cells are arrested in early S-phase because of the HU. Newer protocols suggest that our starvation period was too long to examine the mutant survival under replication stress. Mutant viability was better post-nitrogen stress than without stress, but appeared to decrease by 6 hours in HU (Figure 4.1C). The inconsistency in one of the three flow cytometry experiments is possibly due to the cells' escape from nitrogen starvation in that particular assay, and this could be the reason why we had huge error bars in the septation index (Figure A.1A).

\subsection{Temperature protects cells from future replication stress}

The well-established belief that replication checkpoint mutants are sensitive to HU was altered when we considered transient heat-shock before HU exposure. We hypothesize that high temperature triggers an intra-cellular change that protects cells from further instability or damage. Hereafter, we term the temperature-induced change that may promote survival a "signal". We were able to show that the survival in $\operatorname{mrc1} \Delta$, $\operatorname{cds} 1 \Delta$ and rad3 $\Delta$ in $\mathrm{HU}$ is significantly improved; this survival increases relative to the duration of heat-shock exposure (Figure 4.4A). This indicates that enhanced survival depends directly upon the temperature incubation. The DNA content profile is also altered after $2.5 \mathrm{~h}$ heat-shock compared to 0.5 or $1 \mathrm{~h}$, further suggesting that a cellular signal is established during heat-shock to promote survival in later HU. We conclude that the signal which promotes survival may be established over time in transient pre-stress. Under heat-shock conditions, several genes such as suc22, hsp16, gad8, atf1, etc. are 


\section{Discussion}

overexpressed [44]. These genes either directly or indirectly work during replication stress $[45,47]$. Considering this information, we assumed that an intracellular change or a signal could be the up-regulation of genes involved in a replication stress response pathway. We did not uncover specific changes that temperature triggers to affect survival but this remains in our future work (see Chapter 6).

After release from heat-shock, enhanced viability was seen if the time between heat and HU ("rest") was increased to $30 \mathrm{~min}, 1 \mathrm{hr}$ or $2 \mathrm{hr}$, before decreasing after a $5 \mathrm{hr}$ rest period (Figure 4.5). It appears that the heat-shock induced signal lasts for at least 6 hours ( $2 \mathrm{hr}$ rest $+4 \mathrm{hr}$ in $\mathrm{HU}$, refer to Figure 4.5 for the experimental setup) or two cell division cycles after environmental stress ends. The possible point where the signal effect starts diminishing could be 5 hour resting or the third cell-division cycle $(5 \mathrm{hr}$ rest $+4 \mathrm{hr}$ in $\mathrm{HU}$ ). A minimal G1/S cell proportion and intense 2C DNA content in the beginning of HU treatment suggest that a G2 arrest is induced by heat-shock (Figure 4.6, 4.7). We believe the cells take approximately two hours to release from G2 arrest based on the septation trend in all resting conditions in all indicated strains. The DNA content in the surviving population shows that the mutants are stuck during replication (Figure 4.7). This pattern is similar to the DNA content profile in heat-shock + HU but different from that in $\mathrm{HU}$ alone (Figure 4.2C). Whenever we considered heat-shock for 2.5 hours, the DNA content data in mutants consistently confirmed that cells re-entered into S-phase whereupon cells became stuck in S-phase by HU. One possible reason behind this could be the inhibition of CDK activity, even in the absence of replication checkpoint protein to trigger the repair in mutants and promote survival (see future directions in Chapter 6). Srk1, a substrate of Sty1, inhibits the activity of Cdc25, which is a CDK activator upon oxidative stress [64]. Since heat-shock induces stress response gene expression via Sty1, 


\section{Discussion}

we link this back to our previous argument that the survival in heat-shock $+\mathrm{HU}$ is due to the change or a signal produced within the cell to promote survival. We conclude that a temperature effect, or surviving signal, is built over time and lasts during cell cycle re-entry. This combined action protects replication checkpoint mutants from future HU-induced replication stress.

\subsection{Altered DNA mis-segregation and mutation rates in mutants}

Both wildtype and replication checkpoint mutants exhibit distinctive morphological changes under replication stress, nitrogen depletion, and heat-shock. However, to the best of our knowledge, the combined effect of these stresses on morphology has not been documented. We examined the effect of pre-exposure to environmental stress on cell survival in HU. In agreement with previous findings, wildtype and $\operatorname{chk} 1 \Delta$ were slightly longer consistent with an intact replication checkpoint to delay entry into mitosis $[57,58]$. Mutants $\operatorname{mrc} 1 \Delta$ and $c d s 1 \Delta$ were more elongated because the failing to arrest DNA replication cells acquire DNA damage, triggering the DNA damage checkpoint and causing cell elongation in the presence of HU (Figure 4.8, no stress $+\mathrm{HU}$ ) $[57,58]$. The cut phenotype in rad3s in HU indicates cell entry into mitosis with unreplicated or damaged DNA due to the inactivation of the replication checkpoint as well as the damage checkpoint. When we considered transient exposure to environmental stress, the cell size after heat-shock release or nitrogen re-feed is an indicator of G2 or G1/G0 arrest, respectively (Figure 4.8, A.2). In the presence of HU, heat-shock exposed cells are not as long, while DNA mis-segregation rates also decrease, especially in rad3A (Figure 4.6, 4.8). Nitrogen starved cells seem to regain their normal size by 6 hour in HU (Figure A.2). This, in agreement with our previous argument, further supports that 


\section{Discussion}

long-term nitrogen starved cells take more time to regain normal cell size and cell cycle characteristics. This was also noticed in a previous study using fission yeast [56].

DNA replication stress is a primary cause of increased mutation rate, which is associated with genome instability and cancer (reviewed in $[6,7]$ ). We anticipated that the altered morphological features and abnormal segregation in the surviving populations may be accompanied by altered genome instability. We noticed a moderately elevated mutation rate in temperature stressed $\operatorname{mrc1} \Delta$ and $c d s 1 \Delta$ under $\mathrm{HU}$ induced replication stress. This contrasts with temperature stressed rad3 $\Delta$ survival, in which a strong suppression in the forward mutation rate in HU was observed. We infer that transient high temperature promotes HU survival by protecting genome stability in $\operatorname{rad} 3 \Delta$. We predict that this could happen due to the activation of proteins mimicking checkpoint activity by heat-shock to survive under replication stress.

\subsection{Alternative drug that may cause a similar effect: aphidicolin (APH)}

Replication checkpoint activation is a comprehensive response to the replication stress caused by various impediments, and is not specific to only HU caused replication stress. Therefore, we hypothesize that the temperature effect that alters viability should not be specific to HU. Aphidicolin (APH) is a well-known replication inhibitory drug that is used to cause replication stress and S-phase arrest in human and in vitro budding yeast samples. A dose between $1 \mu \mathrm{M}$ and $10 \mu \mathrm{M}$ was used in both research models [62, 63]. However, the effect of APH has never been tested in fission yeast. Here, we show that these APH doses did not inhibit replication in S. pombe. Although it is possible that 


\section{Discussion}

inhibition of replication in fission yeast could require a higher dose of APH, it raises the question of whether aphidicolin works in fission yeast the same way it does in other research models. Therefore, this remains an area of future investigation. 


\section{Chapter 6}

\section{Conclusions and Future Work}

This chapter succinctly describes the major findings of this study and explains proposed directions and possible approaches.

\subsection{Conclusion}

This study demonstrates that pre-exposure to environmental stress improves viability in replication checkpoint mutants during HU-induced replication stress. We also provide evidence that the environmental stress causes this effect, possibly by pre-conditioning cells to protect them from future danger. Our microscope images and mutation rate analysis reveal the effect of transient heat-shock with respect to DNA segregation and DNA mutation on heat-shock + HU surviving cells. Collectively, our work points to a general cellular response to various environmental stressors that affects cell survival under replication stress, and may be applicable to human disease. 
6 Conclusions and Future Work

\subsection{Model}

We propose a general mechanism of mutant survival in HU after environmental stress based on the interpretation of the data we obtained (Figure 6.1). Activated kinase cascade in response to environmental stress triggers the transcription of CESR genes. As a result, proteins involved in DNA repair and cell cycle regulation under replication stress may overproduced in checkpoint mutants and contribute to the replication checkpoint activation and in adaptation to replication instability. 


\subsection{Future Work}

Based on the deduced knowledge and results, we recognize some of the areas in which future research or development initiatives can be undertaken to find the mechanism behind enhanced survival. We categorize possible future works as follows:

Detecting the phosphorylation of Cdc2: A reason behind the increased replication checkpint mutant viability in heat-shock $+\mathrm{HU}$ could be the inhibition of mitotic entry. A large proportion of cells seemed to be stuck in S-phase in our heat-shock + HU experiments. Since the phosphorylation of Cdc2 stops entry into M-phase, we will test our prediction by checking Cdc2 phosphorylation using a western blot assay.

Measuring the ribonucleotide reductase (RNR) level: RNR is comprised of a large subunit encoded by $c d c 22$ gene and a small subunit encoded by suc22. Upregulation of suc22 (long-isoform) was previously reported in response to heat-shock by Harris et al. [65]. For this reason, we propose that the RNR is accumulated during heat-shock treatment promoting increased RNR enzymatic activity. This may diminish the effect of HU on RNR activity and dNTP levels. Therefore, it is worth testing the level of RNR by qPCR to define whether RNR is influenced by temperature-survival mechanism(s).

Examining the role of SAPK components: Transcription changes are mediated by Sty1 in response to most environmental stresses including heat-shock and replication stress $[44,39]$. As mentioned in Chapter 5 , we expect that SAPK components are involved in the enhanced survival we see. We hypothesize that the SAPK cascade in response to heat-shock regulates the transcription of those genes that are involved in the adaptation $\mathrm{HU}$ effect in checkpoint mutants. This can be tested by making 
double mutants of checkpoint mutants $(\operatorname{rad} 3 \Delta, \operatorname{mrc} 1 \Delta, \operatorname{cds} 1 \Delta, \operatorname{chk} 1 \Delta)$ with stress signaling mutants $($ sty $1 \Delta$, pyp $1 \Delta$, pyp $2 \Delta$, wis $1 \Delta)$, and testing their viability in no stress $+\mathrm{HU}$ and heat-shock $+\mathrm{HU}$.

Determining heat-shock effect on cells in aphidicolin (APH): Since the APH dose has not yet defined in fission yeast, we will first establish this by considering high APH concentrations (10 $\mu \mathrm{M}, 20 \mu \mathrm{M}, 30 \mu \mathrm{M}, 40 \mu \mathrm{M})$. We will test APH in different media to find whether media promotes APH uptake and activity. Once finding a dose with sensitivity in replication mutant strains, a relative viability assay in APH can be performed after heat-shock treatment to determine mutant survival rates.

Checking the survival effect by glucose starvation: We hypothesize that the viability of replication checkpoint mutant survival in HU could be affected by various environmental cues. To confirm this, glucose starvation could be considered since its response in yeast and mammals has well studied. The checkpoint mutant survival in HU can be observed by performing a viability assay described in Chapter 3 . 


\section{Appendix A}

\section{Effect of Nitrogen deprivation on cell survival}

In this appendix, we present the nitrogen deprivation $+\mathrm{HU}$ results from our microscopy and flow cytometry experiments. 
A Effect of Nitrogen deprivation on cell survival 
A Effect of Nitrogen deprivation on cell survival 


\section{References}

[1] A. Mazouzi, G. Velimezi, and J. I. Loizou, "Dna replication stress: Causes, resolution and disease," Experimental Cell Research, vol. 329, no. 1, pp. 85-93, 2014.

[2] I. Magdalou, B. S. Lopez, P. Pasero, and S. A. Lambert, "The causes of replication stress and their consequences on genome stability and cell fate," Seminars in Cell \& Developmental Biology, vol. 30, pp. 154-164, 2014.

[3] E. J. P. Douzery, E. A. Snell, E. Bapteste, F. Delsuc, and H. Philippe, "The timing of eukaryotic evolution: Does a relaxed molecular clock reconcile proteins and fossils?," Proceedings of the National Academy of Sciences of the United States of America, vol. 101, no. 43, pp. 15386-15391, 2004.

[4] "Fission Yeast Cell Cycle." http://www-bcf.usc.edu/ forsburg/main4.html.

[5] V. Wood, R. Gwilliam, M.-A. Rajandream, M. Lyne, R. Lyne, A. Stewart, J. Sgouros, N. Peat, J. Hayles, S. Baker, D. Basham, S. Bowman, K. Brooks, D. Brown, S. Brown, T. Chillingworth, C. Churcher, M. Collins, R. Connor, A. Cronin, P. Davis, T. Feltwell, A. Fraser, S. Gentles, A. Goble, N. Hamlin, D. Harris, J. Hidalgo, G. Hodgson, S. Holroyd, T. Hornsby, S. Howarth, E. J. Huckle, S. Hunt, K. Jagels, K. James, L. Jones, M. Jones, S. Leather, S. McDonald, J. McLean, P. Mooney, S. Moule, K. Mungall, L. Murphy, D. Niblett, C. Odell, K. Oliver, S. O'Neil, D. Pearson, M. A. Quail, E. Rabbinowitsch, K. Rutherford, S. Rutter, D. Saunders, K. Seeger, S. Sharp, J. Skelton, M. Simmonds, R. Squares, S. Squares, K. Stevens, K. Taylor, R. G. Taylor, A. Tivey, S. Walsh, T. Warren, S. Whitehead, J. Woodward, G. Volckaert, R. Aert, J. Robben, B. Grymonprez, I. Weltjens, E. Vanstreels, M. Rieger, M. Schafer, S. Muller-Auer, C. Gabel, M. Fuchs, C. Fritzc, E. Holzer, D. Moestl, H. Hilbert, K. Borzym, I. Langer, A. Beck, H. Lehrach, R. Reinhardt, T. M. Pohl, P. Eger, W. Zimmermann, H. Wedler, R. Wambutt, B. Purnelle, A. Goffeau, E. Cadieu, S. Dreano, S. Gloux, V. Lelaure, S. Mottier, F. Galibert, S. J. Aves, Z. Xiang, C. Hunt, K. Moore, S. M. Hurst, M. Lucas, M. Rochet, C. Gaillardin, V. A. Tallada, A. Garzon, G. Thode, R. R. Daga, L. Cruzado, J. Jimenez, M. Sanchez, F. del Rey, J. Benito, A. Dominguez, J. L. Revuelta, S. Moreno, J. Armstrong, S. L. Forsburg, L. Cerrutti, 


\section{References}

T. Lowe, W. R. McCombie, I. Paulsen, J. Potashkin, G. V. Shpakovski, D. Ussery, B. G. Barrell, and P. Nurse, "The genome sequence of Schizosaccharomyces pombe," Nature, vol. 415, pp. 871-880, Feb. 2002.

[6] S. A. Sabatinos and S. L. Forsburg, "Preserving the Replication Fork in Response to Nucleotide Starvation: Evading the Replication Fork Collapse Point," in The Mechanisms of DNA Replication (D. Stuart, ed.), p. Ch. 08, Rijeka: InTech, Feb. 2013. DOI: $10.5772 / 51393$.

[7] D. Branzei and M. Foiani, "Maintaining genome stability at the replication fork," Nature Reviews Molecular Cell Biology, vol. 11, no. 3, pp. 208-219, 2010.

[8] "replication fork stalling and the fork protection complex."

[9] W. Feng, S. C. Di Rienzi, M. K. Raghuraman, and B. J. Brewer, "Replication stress-induced chromosome breakage is correlated with replication fork progression and is preceded by single-stranded dna formation," G3\#58;

Genes|Genomes|Genetics, vol. 1, no. 5, pp. 327-335, 2011.

[10] A. Y. Tagger, J. Boux, and J. A. Wright, "Hydroxy[14c]urea uptake by normal and transformed human cells: evidence for a mechanism of passive diffusion," Biochemistry and Cell Biology, vol. 65, no. 11, pp. 925-929, 1987.

[11] A. L. Walker, R. M. Franke, A. Sparreboom, and R. E. Ware, "Transcellular movement of hydroxyurea is mediated by specific solute carrier transporters," Experimental Hematology, 2011.

[12] E. Wawra and E. Wintersberger, "Does hydroxyurea inhibit dna replication in mouse cells by more than one mechanism?," Molecular and Cellular Biology, vol. 3, no. 3, pp. 297-304, 1983.

[13] I. H. Krakoff, N. C. Brown, and P. Reichard, "Inhibition of ribonucleoside diphosphate reductase by hydroxyurea," Cancer Research, vol. 28, no. 8, pp. 1559-1565, 1968.

[14] J. Stubbe and P. Riggs-Gelasco, "Harnessing free radicals: formation and function of the tyrosyl radical in ribonucleotide reductase," Trends in Biochemical Sciences, vol. 23, no. 11, pp. 438-443, 1998.

[15] G. Lassmann, L. Thelander, and A. Gräslund, "Epr stopped-flow studies of the reaction of the tyrosyl radical of protein $\mathrm{r} 2$ from ribonucleotide reductase with hydroxyurea," Biochemical and Biophysical Research Communications, vol. 188, no. 2, pp. 879-887, 1992. 


\section{References}

[16] P. E. R. P. Bianchi, V., "Changes of deoxyribonucleoside triphosphate pools induced by hydroxyurea and their relation to dna synthesis," THE JOURNAL OF BIOLOGICAL CHEMISTRY, vol. 261, no. 34, pp. 16037-16042, 1986.

[17] A. Koç, L. J. Wheeler, C. K. Mathews, and G. F. Merrill, "Hydroxyurea arrests dna replication by a mechanism that preserves basal dntp pools," Journal of Biological Chemistry, vol. 279, no. 1, pp. 223-230, 2003.

[18] A. Singh and Y.-J. Xu, "The cell killing mechanisms of hydroxyurea," Genes, vol. 7, no. 11, p. 99, 2016.

[19] E. Petermann, M. L. Orta, N. Issaeva, N. Schultz, and T. Helleday, "Hydroxyurea-stalled replication forks become progressively inactivated and require two different rad51-mediated pathways for restart and repair," Molecular Cell, vol. 37, no. 4, pp. 492-502, 2010.

[20] M. Kai, "Replication checkpoint kinase cds1 regulates mus81 to preserve genome integrity during replication stress," Genes \& Development, vol. 19, no. 8, pp. 919-932, 2005.

[21] N. J. Bentley, D. A. Holtzman, G. Flaggs, K. S. Keegan, A. DeMaggio, J. C. Ford, M. Hoekstra, and A. M. Carr, "The Schizosaccharomyces pombe rad3 checkpoint gene.," The EMBO Journal, vol. 15, pp. 6641-6651, Dec. 1996.

[22] L. Zou, D. Liu, and S. J. Elledge, "Replication protein a-mediated recruitment and activation of rad17 complexes," Proceedings of the National Academy of Sciences, vol. 100, no. 24, pp. 13827-13832, 2003.

[23] X. Wang, L. Zou, T. Lu, S. Bao, K. E. Hurov, W. N. Hittelman, S. J. Elledge, and L. Li, "Rad17 phosphorylation is required for claspin recruitment and chk1 activation in response to replication stress," Molecular Cell, vol. 23, no. 3, pp. 331-341, 2006.

[24] H. D. Lindsay, D. J. Griffiths, R. J. Edwards, P. U. Christensen, J. M. Murray, F. Osman, N. Walworth, and A. M. Carr, "S-phase-specific activation of cds1 kinase defines a subpathway of the checkpoint response in schizosaccharomyces pombe," Genes \& Development, vol. 12, no. 3, pp. 382-395, 1998.

[25] Y.-j. Xu, "Two-stage mechanism for activation of the dna replication checkpoint kinase cds1 in fission yeast," Genes \& Development, vol. 20, no. 8, pp. 990-1003, 2006.

[26] A. A. Alcasabas, A. J. Osborn, J. Bachant, F. Hu, P. J. H. Werler, K. Bousset, K. Furuya, J. F. Diffley, A. M. Carr, and S. J. Elledge, "Mrc1 transduces signals of DNA replication stress to activate Rad53," Nat Cell Biol, vol. 3, pp. 958-965, Nov. 2001. 


\section{References}

[27] H. Zhao, K. Tanaka, E. Nogochi, C. Nogochi, and P. Russell, "Replication checkpoint protein mrc1 is regulated by rad3 and tel1 in fission yeast," Molecular and Cellular Biology, vol. 23, no. 22, pp. 8395-8403, 2003.

[28] B. Furnari, A. Blasina, M. N. Boddy, C. H. McGowan, and P. Russell, "Cdc25 inhibited in vivo and in vitro by checkpoint kinases cds1 and chk1," Molecular Biology of the Cell, vol. 10, no. 4, pp. 833-845, 1999.

[29] T. Caspari and A. M. Carr, "Dna structure checkpoint pathways in schizosaccharomyces pombe," Biochimie, vol. 81, no. 1, pp. 173 - 181, 1999.

[30] I. Miyabe, T. Morishita, H. Shinagawa, and A. M. Carr, "Schizosaccharomyces pombe cds1chk2 regulates homologous recombination at stalled replication forks through the phosphorylation of recombination protein rad60," Journal of Cell Science, vol. 122, no. 20, pp. 3638-3643, 2009.

[31] I. Miyabe, T. Morishita, T. Hishida, S. Yonei, and H. Shinagawa, "Rhp51-dependent recombination intermediates that do not generate checkpoint signal are accumulated in schizosaccharomyces pombe rad60 and smc5/6 mutants after release from replication arrest," Molecular and Cellular Biology, vol. 26, no. 1, pp. 343-353, 2005.

[32] S. A. Sabatinos, M. D. Green, and S. L. Forsburg, "Continued dna synthesis in replication checkpoint mutants leads to fork collapse," Molecular and Cellular Biology, vol. 32, no. 24, pp. 4986-4997, 2012.

[33] N. Willis and N. Rhind, "The fission yeast rad32(mre11)-rad50-nbs1 complex acts both upstream and downstream of checkpoint signaling in the s-phase dna damage checkpoint," Genetics, vol. 184, no. 4, pp. 887-897, 2010.

[34] H. Capasso, "Phosphorylation activates chk1 and is required for checkpoint-mediated cell cycle arrest," Journal of Cell Science, vol. 115, no. 23, pp. 4555-4564, 2002.

[35] Y. Saka, F. Esashi, T. Matsusaka, S. Mochida, and M. Yanagida, "Damage and replication checkpoint control in fission yeast is ensured by interactions of crb2, a protein with brct motif, with cut5 and chk1," Genes \& Development, vol. 11, no. 24, pp. 3387-3400, 1997.

[36] C. L. Lawrence, H. Maekawa, J. L. Worthington, W. Reiter, C. R. M. Wilkinson, and N. Jones, "Regulation ofschizosaccharomyces pombeatf1 protein levels by sty1-mediated phosphorylation and heterodimerization with pcr1," Journal of Biological Chemistry, vol. 282, no. 8, pp. 5160-5170, 2006. 


\section{References}

[37] T. Takeda, T. Toda, K. Kominami, A. Kohnosu, M. Yanagida, and N. Jones, "Schizosaccharomyces pombe atf1+ encodes a transcription factor required for sexual development and entry into stationary phase.," The EMBO Journal, vol. 14, pp. 6193-6208, Dec. 1995.

[38] A. N. Nguyen and K. Shiozaki, "Heat shock-induced activation of stress map kinase is regulated by threonine- and tyrosine-specific phosphatases," Genes \& Development, vol. 13, no. 13, pp. 1653-1663, 1999.

[39] L. Taricani, H. E. Feilotter, C. Weaver, and P. G. Young, "Expression of hsp16 in response to nucleotide depletion is regulated via the spc1 MAPK pathway in Schizosaccharomyces pombe," Nucleic Acids Research, vol. 29, pp. 3030-3040, July 2001.

[40] S. Hartmuth and J. Petersen, "Fission yeast tor1 functions as part of torc1 to control mitotic entry through the stress mapk pathway following nutrient stress," Journal of Cell Science, vol. 122, no. 11, pp. 1737-1746, 2009.

[41] M. Schonbrun, M. Kolesnikov, M. Kupiec, and R. Weisman, "Torc2 is required to maintain genome stability during s phase in fission yeast," Journal of Biological Chemistry, vol. 288, no. 27, pp. 19649-19660, 2013.

[42] K. Ikeda, S. Morigasaki, H. Tatebe, F. Tamanoi, and K. Shiozaki, "Fission yeast tor complex 2 activates the agc-family gad8 kinase essential for stress resistance and cell cycle control," Cell Cycle, vol. 7, no. 3, pp. 358-364, 2008.

[43] M. Kawai, A. Nakashima, M. Ueno, T. Ushimaru, K. Aiba, H. Doi, and M. Uritani, "Fission yeast tor1 functions in response to various stresses including nitrogen starvation, high osmolarity, and high temperature," Current genetics, vol. 39, pp. 166-174, May 2001.

[44] D. Chen, W. M. Toone, J. Mata, R. Lyne, G. Burns, K. Kivinen, A. Brazma, N. Jones, and J. Bähler, "Global Transcriptional Responses of Fission Yeast to Environmental Stress," Molecular Biology of the Cell, vol. 14, pp. 214-229, Jan. 2003.

[45] Z. Chu, J. Li, M. Eshaghi, X. Peng, R. K. M. Karuturi, and J. Liu, "Modulation of cell cycle-specific gene expressions at the onset of s phase arrest contributes to the robust dna replication checkpoint response in fission yeas," Molecular Biology of the Cell, vol. 18, no. 5, pp. 1756-1767, 2007.

[46] A. Watson, J. Mata, J. Bähler, A. Carr, and T. Humphrey, "Global Gene Expression Responses of Fission Yeast to Ionizing Radiation," Molecular Biology of the Cell, vol. 15, pp. 851-860, Feb. 2004. 


\section{References}

[47] A. Herlihy and R. de Bruin, "The role of the transcriptional response to dna replication stress," Genes, vol. 8, no. 3, p. 92, 2017.

[48] B. M. Hall, C.-X. Ma, P. Liang, and K. K. Singh, "Fluctuation AnaLysis CalculatOR: a web tool for the determination of mutation rate using Luria-Delbrück fluctuation analysis," Bioinformatics, vol. 25, pp. 1564-1565, June 2009.

[49] S. A. Sabatinos and S. L. Forsburg, "Molecular genetics of schizosaccharomyces pombe," Methods in Enzymology, vol. 470, pp. 759 - 795, 2010. Guide to Yeast Genetics: Functional Genomics, Proteomics, and Other Systems Analysis.

[50] S. A. Sabatinos and S. L. Forsburg, Measuring DNA Content by Flow Cytometry in Fission Yeast, pp. 449-461. Totowa, NJ: Humana Press, 2009.

[51] M. Polanshek, "Effects of heat shock and cycloheximide on growth and division of the fission yeast, schizosaccharomyces pombe. with an appendix. estimation of division delay for s. pombe from cell plate index curves," Journal of Cell Science, vol. 23, no. 1, pp. 1-23, 1977.

[52] J. Erenpreisa, A. Ivanov, G. Dekena, A. Vitina, R. Krampe, T. Freivalds, G. Selivanova, and H. Roach, "Arrest in metaphase and anatomy of mitotic catastrophe: Mild heat shock in two human osteosarcoma cell lines," Cell Biology International, vol. 24, no. 2, pp. 61-70, 2000.

[53] S. L. Forsburg and N. Rhind, "Basic Methods for Fission Yeast," Yeast (Chichester, England), vol. 23, pp. 173-183, Feb. 2006.

[54] Y.-j. Xu, A. Singh, and G. M. Alter, "Hydroxyurea induces cytokinesis arrest in cells expressing a mutated sterol-14 $\alpha$-demethylase in the ergosterol biosynthesis pathway," Genetics, vol. 204, no. 3, pp. 959-973, 2016.

[55] M. Eshaghi, R. K. M. Karuturi, J. Li, Z. Chu, E. T. Liu, and J. Liu, "Global Profiling of DNA Replication Timing and Efficiency Reveals that Efficient Replication/Firing Occurs Late during S-Phase in S. pombe," PLoS ONE, vol. 2, no. 8, p. e722, 2007.

[56] S. Su, Y. Tanaka, I. Samejima, K. Tanaka, and M. Yanagida, "A nitrogen starvation-induced dormant $\mathrm{g} 0$ state in fission yeast: the establishment from uncommitted g1 state and its delay for return to proliferation," Journal of Cell Science, vol. 109, no. 6, pp. 1347-1357, 1996.

[57] K. Tanaka and P. Russell, "Mrc1 channels the DNA replication arrest signal to checkpoint kinase Cds1," Nat Cell Biol, vol. 3, pp. 966-972, Nov. 2001. 


\section{References}

[58] H. Zhao and P. Russell, "Dna binding domain in the replication checkpoint protein mrc1 of schizosaccharomyces pombe.," The Journal of biological chemistry, vol. 279 51, pp. 53023-7, 2004.

[59] D. Brusick, "Principles of genetic toxicology. second edition," Trends in Pharmacological Sciences, vol. 9, no. 4, p. 148, 1988.

[60] "Canavanine Lab." https://biology.mit.edu/sites/default/files/Canavanine\%20Lab.pdf.

[61] S. A. Sabatinos, T. L. Mastro, M. D. Green, and S. L. Forsburg, "A Mammalian-Like DNA Damage Response of Fission Yeast to Nucleoside Analogs," Genetics, vol. 193, pp. 143-157, Jan. 2013.

[62] H. Krokan, E. Wist, and R. H. Krokan, "Aphidicolin inhibits DNA synthesis by DNA polymerase alpha and isolated nuclei by a similar mechanism.," Nucleic Acids Research, vol. 9, pp. 4709-4719, Sept. 1981.

[63] P. Plevani, G. Badaracco, E. Ginelli, and S. Sora, "Effect and mechanism of action of aphidicolin on yeast deoxyribonucleic acid polymerases.," Antimicrobial Agents and Chemotherapy, vol. 18, pp. 50-57, July 1980.

[64] S. López-Avilés, M. Grande, M. González, A.-L. Helgesen, V. Alemany, M. Sanchez-Piris, O. Bachs, J. B. Millar, and R. Aligue, "Inactivation of the cdc25 phosphatase by the stress-activated srk1 kinase in fission yeast," Molecular Cell, vol. 17, no. 1, pp. 49 - 59, 2005.

[65] P. Harris, P. J. Kersey, C. J. McInerny, and P. A. Fantes, "Cell cycle, dna damage and heat shock regulate suc22+ expression in fission yeast.," Molecular and General Genetics, vol. 252, no. 3, pp. 284-291, 1996. 